\title{
Taxes in the Time of Revolution: An Experimental Test of the Rentier State during Algeria's Hirak*
}

\author{
Robert Kubinec and Helen V. Milner
}

April 27, 2022

\begin{abstract}
We examine the rentier thesis that a government's control over oil resources should help it resist pressures for democratization. Our online survey experiment, implemented during a nation-wide mobilization for regime change in Algeria known as the Hirak, used interactive experimental treatments to provide information about the Algerian government's subsidies for fuel resources and low value-added taxes. Based on a sample of 5,968 Algerians, we find that when Algerians learn about their country's relatively high level of fuel subsidies and low level of taxes, their assessments of the government's performance improves. However, results for outcomes involving demands for representation, such as joining the protest movement, reveal that wealthier respondents became less willing to protest following treatment whereas poorer respondents became more willing to protest. As a result, we believe that the rentier state may be capable of encouraging support from wealthier citizens, yet still permit mass mobilization if redistribution is perceived as being co-opted by the wealthy.
\end{abstract}

${ }^{*}$ We thank Michael Ross, Benjamin Graham, David Waldner, Giuliana Pardelli, Aaron Kaufman, Joan Barcelo and participants in the New York University Abu Dhabi political science seminar for helpful comments on this draft. 
The rentier theory, one of the longest standing conjectures of the determinants of regime type in comparative political science, argues that a state's control over natural resources is likely to promote a more authoritarian form of government (Ross 2001; Herb 2005; Beblawi and Luciani 1987). The theory, which originated in the analysis of oil-rich states in the Middle East (Crystal 1990; Beblawi and Luciani 1987; Ayubi 1995), has been shown to be a compelling factor in authoritarianism through a wealth of cross-national studies, showing a robust association between the level of oil wealth and dictatorship, particularly since the 1970s (Ross 2015). In this paper, we experimentally test one of the core components of the rentier state theory: to what extent citizens limit their demands for representative government in response to changes in receipts of oil-funded benefits from their non-democratic government (Paler 2013; Cuesta et al. 2019).

This theory involves the taxation-representation trade-off (Levi 1989; Tilly 1992; Prichard 2015). A state's control over oil resources provides it with a source of revenue which does not require regular tax collection or compliance, reducing citizen leverage in bargaining with the ruler over control of the resources. Our intention is not to test whether oil rents and taxes are actually substitutes-we assume that they are -but rather whether the alleged reduction in taxes empirically reduces demands for representative, and ultimately democratic, government.

Testing whether this trade-off between oil rents and democratic aspirations exists is difficult because episodes of regime change are necessarily rare. To provide useful data, we examined a recent wave of popular mobilization in Algeria during 2019 known as the Hirak. This national protest movement endured for months up until the outbreak of the COVID-19 pandemic in 2020, and successfully forced the long-standing president, Abdelaziz Bouteflika, out of office. We fielded an online survey for several months during the early period of the protest movement from April to July 2019, recruiting a diverse sample of 5,968 Algerians. In our survey we embedded an interactive experiment which asked respondents for the amount they had spent on fuel subsidies and on goods covered by the value-added tax (VAT). To 
provide a plausible counterfactual per the rentier theory of an oil-free Algeria, we then showed them the increased amount they would spend on these items if they lived in Tunisia, a neighboring country which recently transitioned to democracy and does not have extensive fuel resources. We supplemented these individualized treatments with a general informational message showing that the Algerian state's reliance on oil revenues has increased in recent years.

Our results show that the treatments improved respondents' perceptions of the government's performance, measured as its ability to combat corruption, provide public goods, implement reforms and guard stability. However, we found that the treatments' effects on political actions involving demands for accountability are heavily conditioned by the respondent's wealth. Wealthier respondents were much less likely to report a desire to join the protest movement upon receiving the treatment, while the opposite held for poorer respondents. Furthermore, the overall positive effects of the treatment on attitudes toward government performance are likewise concentrated among wealthier respondents. As such, while we find that the rentier state's perceived bias in favor of wealthier citizens undermined support for the regime among those at the lower end of the wealth distribution.

On the whole, these results suggest that authoritarian rentier states may struggle with the equitable provision of benefits across class divides, undermining the rentier state's ability to suppress dissent.

\section{Background}

The rentier state is a theory that has profoundly influenced political science research since Mahdavy (1970), Beblawi and Luciani (1987), Karl (1997) and Anderson (1987) explored the effects of oil resources on the nature of political institutions in the Middle East and Latin America. Since that time, a growing literature has documented strong associations between the presence of oil resources and more authoritarian forms of government (Ross 
2001, 2012, 2015; Andersen and Ross 2014). However, it is difficult to narrow down the full range of theories to a precise set of causal factors (Smith and Waldner 2021). Scholarship has shown that the effect of oil on regime type may be conditional on a range of factors, such as the timing of regime change (Houle 2018), the degree of industrialization (Brooks and Kurtz 2016), and the presence of income inequality (Dunning 2008). While we acknowledge the many strands of the theory, in this article we focus primarily on the contention that oil revenues may reduce demand for representation via lessening citizens' tax burden in exchange for public and private goods. There are other core components of the rentier thesis, especially that oil increases a state's repressive capacity (Ross 2001; Bellin 2004; Brownlee, Masoud, and Reynolds 2015), which can prevent regime change from occurring even if the majority of the population favors it.

Given these other factors, the taxation-representation trade-off can be seen as a necessary, but not sufficient, condition for democratization. Early modern European states' demands for revenue and consequent increases in taxation are strongly linked to both increases in state infrastructural power and demands for more representation in the government (Weiss and Hobson 1995; Dincecco 2009; Levi 1989). Recent studies show that this historical pattern also tends to hold among contemporary states as states that collect fewer taxes are also less democratic (Slater, Smith, and Nair 2014). This feature of contemporary state development may be explained by the widespread availability of sovereign finance that encouraged state expansion without the need for growing the tax base (Migdal 1988; Queralt 2019). As such, the taxation mechanism remains one of the best explanations for how a state's reliance on oil revenues could lead to more authoritarian government by reducing citizen claims on the state (Jones 2017). If a state does not require citizens to contribute to its coffers, while still maintaining an acceptable level of public goods, then it may prevent redistributive conflicts because the cost of collective action to oppose the state is far greater than the benefits of the status quo.

However, the rentier state theory has its critics who allege that the theory is based on 
flawed cross-sectional comparisons (Waldner, Peterson, and Shoup 2015; Herb 2005). The theory seems to best explain resource-dependent countries in the Middle East, which also happens to be the most authoritarian region in the world (Jamal and Tessler 2008). Despite the durability of authoritarian regimes in the region, it does not necessarily follow that authoritarianism is caused by states' discovery of oil resources. Rather, there could be early factors in state development which predisposed Arab governments to form more authoritarian governments. The subsequent exploration of oil resources may have served to lengthen a given leader's tenure but may not have affected the leader's propensity to use authoritarian means to retain power, as plausibly occurred in the Arabian Gulf in the first half of the 20th century (Waldner and Smith 2021). Furthermore, oil resources are associated with negative outcomes that could shorten regime tenure, such as the outbreak of civil wars (Ross 2006; Fjelde 2009) and a reduction in economic development, the so-called Dutch disease (Corden 1984).

The main challenge in adjudicating these rival positions is the fact that we are studying a variable which we can almost never experimentally manipulate: oil resources. For example, to understand with confidence whether oil resources are the main prop behind the Saudi Arabia's long-lived monarchical regime, it would be necessary to observe a Saudi Arabia both with and without oil resources. Comparing Saudi Arabia to other wealthy authoritarian nations such as Singapore is a limited form of inference as it is hard to find an appropriate comparison country. Furthermore, cross-sectional comparisons can obscure important anomalies, such as Kuwait, a country with ample oil resources yet also the longest-lived parliament in the Arab world (Crystal 1990; Gandhi 2008). Exploiting within-country variation in oil resources can at least partially alleviate these concerns (Ross 2015), but because oil resources are not exogenous to political development (Waldner and Smith 2021), it is difficult to make fully identified causal inferences from panel data alone.

In addition, we note that employing country-year observations introduces an ecological inference problem (King 1997). The theory operates on individuals, or at a minimum salient class-based groups, but aggregate measures of oil resources and outcomes such as levels of 
democracy obscure heterogeneity in individuals' responses to the rentier state. While limited to date, experimental approaches have shed light on the taxation-representation trade-off at the micro level. Paler (2013) provided initial support for the trade-off by showing that citizens in resource-rich areas expressed greater demands for accountability following the discovery of resources. Quasi-experimentally, Gadenne (2017) showed that Brazilian municipalities were more likely to invest increases in revenues from taxes in public goods like education, but not so with "unearned" revenues like grants, which the municipalities used for discretionary projects. Cuesta et al. (2019) finds that accountability demands by citizens depend on citizens' perceptions of ownership over the revenue, not just its source. In other words, citizens of rentier states do not blithely ignore the government, but rather conditionally support the regime if it is seen as meeting its implicit contract to share the wealth (Ross 2012, 67).

What is important to the taxation-representation trade-off is the counterfactual: what would citizens demand if the regime did not have access to oil resources? If the theory holds, then reduced oil revenue should lead to increased taxation and subsequent demands for representation. It is this central principle that we seek to test experimentally by examining demands for the strongest form of accountability: regime change.

Additionally, we are interested in the conditional effects of the rentier state in terms of inequality. It seems to follow logically that a person's position in the wealth distribution would affect how they perceive government largesse. The poorest may not spend as much on goods covered by taxes or earn enough income for tax benefits to become appreciably large. By comparison, if the rentier state focused more on pro-poor policies like conditional cash transfers and subsidized housing, they might be able to affect the views of the poor to a higher degree (Magaloni and Kricheli 2010; De La O 2013). In fact, if the poor perceive the rich as obtaining more of the benefits of the rentier state due to increasing inequality (Haggard and Kaufman 2012), then there is reason to believe that the rentier state could help create grievances rather than suppress them. For these reasons, in addition to the overall effect of the rentier state on actions and attitudes towards democracy, we also want to know 
whether its effects are conditional on factors we have reason to believe should matter for the comparative value of benefits obtained from the state.

\section{Algeria During the Hirak}

We focus on Algeria as an excellent case for examining the taxation-representation tradeoff proposed by rentier theory because, over the last twenty years, the regime has had to face challenges to its patronage and welfare benefits due to population growth. Most recently, Algeria's Hirak protest movement in 2019 provided an ideal context in which to investigate the efficacy of the rentier state as it represented a rare episode of mass contention in a state with significant oil resources. While Algeria's petroleum resources never reached a per capita level of the small Gulf states, it possesses a considerable share of the world's oil resources12.2 billion barrels of proven reserves-and for decades was able to sustain a quality of life above the regional average for its citizens. In addition to its natural resource endowments, Algeria is distinctive for its long-lived authoritarian regime.

Algeria has had authoritarian government since its hard-fought independence from France in 1962. Starting with the revolutionary leader Ahmed Ben Bella in the 1960s, Algeria experienced a series of dictators who relied on the unquestioned dominance of the armed forces to maintain control. The security state further survived a decade-long war with the Islamic Salvation Front following botched elections in 1992, ending with the election of Abdelaziz Bouteflika to the presidency in 1999. Though Bouteflika did not have a military career, he was elected with the military's support, and he preserved the military's prerogatives over budgeting and lucrative economic enterprises (Dillman 2000). On the whole, after the conclusion of the civil war of the 1990s, Algeria remained quite stable during Bouteflika's rule until the outbreak of the Hirak protests.

While it would be unrealistic to chalk up the regime's longevity solely due to oil, the presence of a high level of natural resources appeared to paper over the diminished legitimacy of the regime as the war for independence became a distant memory. One of the best examples 
Figure 1: Algerian Fiscal Capacity and Oil Rents

A

\section{Government Revenue}

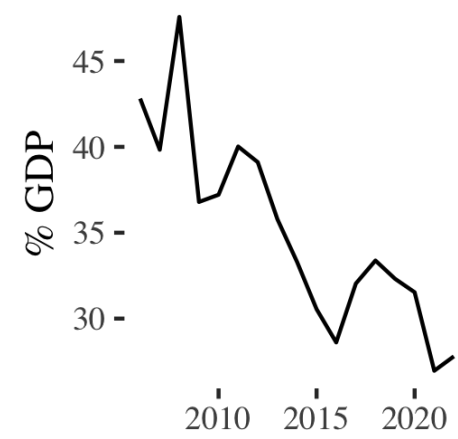

B

Non-Oil

Fiscal Balance

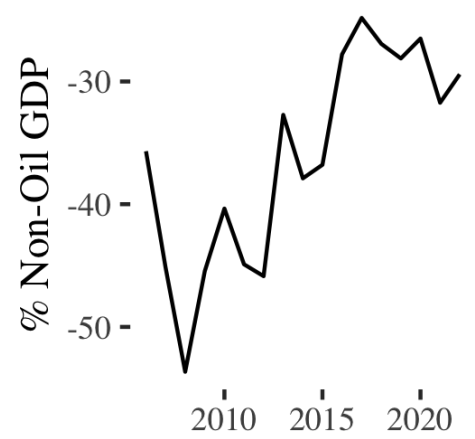

C

\section{Breakeven Fiscal Oil Price}

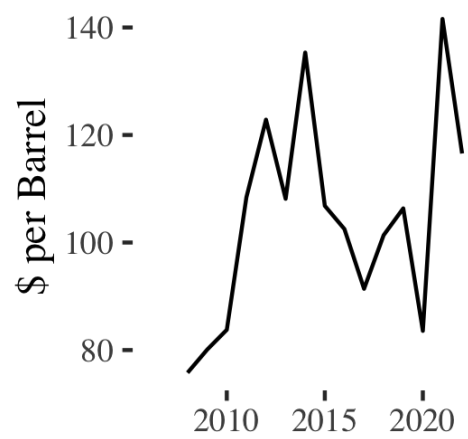

Statistical information taken from the FRED data repository of the St. Louis Federal Reserve Bank.

of the regime's employment of rent to counter instability occurred during the Arab Spring, which started in neighboring Tunisia in late 2010. Although protests did spread from Tunisia to Algeria in the spring of 2011, an increase in government spending on food subsidies appeared to keep the protests from spiraling out of control. ${ }^{1}$ Bouteflika further announced liberalization measures, which while partial and ultimately lacking implementation, increased benefits for Algeria's citizens. ${ }^{2}$

While analysts acknowledge this largesse as contributing to the regime's stability, it was also clear that the rentier state might not always deliver. As Lahcen Achy wrote in 2012, "if the price of oil suddenly drops, reducing the government's ability to control the budget deficit, this could fuel popular anger... to me, it is only a matter of time." Similarly, Yahia Zoubir opined in 2016 that "strikes, protests and riots are routine," although "the regime has been able to address them through payoffs in the form of higher salaries or housing vouchers."

The regime's problems came from the fact that, although its natural resource revenues

1. See https://www.iemed.org/publication/the-arab-spring-is-algeria-the-exception/.

2. See https://www.iemed.org/publication/the-arab-spring-is-algeria-the-exception/ 
remained quite large, they did not increase in tandem with Algeria's population, creating stress on patronage policies and public good provision. Algeria, like many other Arab states, used state-led development to create a new middle class that depended on a stable supply of government jobs as a path to advancement (Diwan 2013). The macroeconomic data for Algeria shown in Figure 1 reveals the declining coverage of government expenses with oil receipts. Between 2010 and 2020, government expenditure as a percent of GDP in panel A in Figure 1 declined from the high 40s to the low 30s. At the same time, the fiscal balance of the government in terms of non-oil GDP (panel B), which is a measure of the extent to which the government relies on oil revenues, declined from $-50 \%$ to about $-30 \%$. The reason for these declines had to do with the needs of a growing population and largely flat oil production at around 500,000 bpd. Consequently, the breakeven oil price in panel $\mathrm{C}$ grew from under $\$ 80 /$ barrel at the start of the decade to more than $\$ 120 /$ barrel by the end, which left the government in an unsustainable fiscal position.

As such, while the system proved remarkably durable during the Arab Spring, informed observers had noted cracks in the rentier system. However, these conditions existed for some years before an aging Bouteflika, troubled with poor health, nonetheless decided to push for a fifth term as president. Algerian activists seized the moment, and on February 22, 2019, "millions of Algerians" participated in a march demanding Bouteflika's resignation. ${ }^{3}$ While survey data is limited, up to 50 percent of Algerians may have shown interest in turning out to protest during the movement's high point in the spring and summer of 2019 (Grewal, Kilavuz, and Kubinec 2019). Remarkably, this high level of participation continued for months as Algerians turned out each Friday, making use of focal points to sustain momentum (Ketchley and Barrie 2020). While the protests decreased in size, the weekly activism only ended when COVID-19 cases appeared in Algeria and the government mandated an end to gatherings. ${ }^{4}$

The Hirak's main achievement came from forcing Bouteflika to step aside, one of its

3. See https://www.hrw.org/news/2022/02/21/algeria-3-years-repression-protest-tightens

4. See https://www.arab-reform.net/publication/the-future-of-the-algerian-hirak-following-the-covid-19-pandemic/ 
original demands. However, the movement was unable to stop the election of another regime insider, Abdelmadjid Tebboune, to the presidency in December of 2019. ${ }^{5}$ Because of these limited successes, it is important to note that state spending on salaries and welfare measures was not the only way that oil wealth influenced the success of the protest movement. Algeria's military is also much larger than its neighbors and oil rents helped fund their security apparatus that targeted protest leaders (Brownlee, Masoud, and Reynolds 2015, 52-55). While Bouteflika's resignation signaled an important victory for the protesters, it is clear that the movement did not ultimately succeed in regime change (Grewal 2021).

For this reason, the "pouvoir", or system of elites, that many activists sought to destroy remains intact as of the spring of 2022. Even though Algeria's oil largesse provided housing, jobs and education, it is still true that the military and affiliated political elites captured the lion's share of the rentier system's benefits (Dillman 2000). While Algeria's revolution replaced the French occupiers, over time it created a new, domestic elite who had no qualms about ensuring their continued access to valuable rents. As such, Algeria is no exception to the patterns of crony capitalism and corruption prevalent in the region (Malik, Atiyas, and Diwan 2020). Replacing the leader without affecting the system that reproduced these inequalities could not result in lasting change, as the protest organizers' well knew.

Concerns over elite bias in institutions figured prominently in the protest movement, suggesting that wealth endowments may have affected how people perceived the relative importance of the rentier state. Survey data from the Arab Barometer in 2019 found a plurality of respondents (41\%) cited corruption and the quality of public services as the most important issues facing the country (Robbins 2019, 4). Unsurprisingly, the government's response to the Hirak was to appear as though it was rooting out corruption, indicting prominent regime figures and businesspeople on abuse of power and unjust enrichment (Marwane 2021). As a result, we have prior reason to believe that not only the quality of the rentier state was at issue, but also whether benefits were being equitably distributed across class divides in the

5. See https://www.hrw.org/news/2022/02/21/algeria-3-years-repression-protest-tightens 
country.

To summarize, during an episode of regime contention like the Hirak it is clear that there were a significant number of people who were upset with the regime's policies and, by extension, with the performance and legitimacy of the rentier state. Given the salience of the issue, it would seem to be an appropriate time to ascertain to what extent the rentier nature of Algerian institutions helps depress protests. By the presence of protests we might infer that the rentier state's depressive effect on grievances is weaker than it was before, and the very real nature of regime contention also suggests that the rentier state's future is far from certain. For this reason, there should be a substantial number of people who, on the margin, might change their perspectives about the performance and legitimacy of the regime given new information.

\section{Research Design}

Our research design aims to experimentally test the taxation-representation part of rentier theory using individual level data in a country undergoing a regime transition. While we cannot manipulate Algerian institutions or oil deposits, we can influence the available data respondents have about the generosity of their rentier state in regional comparison. We pre-registered two hypotheses prior to our study, which we list below:

H1: A higher level of gasoline subsidies relative to neighboring democratic countries will encourage pro-regime attitudes and actions among citizens in a dictatorship.

H2: A lighter tax burden relative to neighboring democratic countries will encourage pro-regime attitudes and actions among citizens in a dictatorship.

As with any manipulation, we need to be aware of what the range of plausible counterfactuals is. It would seem impractical to try to compare Algeria to a counterfactual Algeria 
without oil or a counterfactual Algeria with democracy: presumably so many other institutional and political variables would also change such that posing such a comparison to Algerians would result in unintelligible answers.

Instead, we compare Algeria to its immediate neighbor, Tunisia. Tunisia is a natural reference point because it has a long shared history with its neighbor, including decades spent under French colonization and similarly authoritarian institutions in the post-colonial period. However, Tunisia is different from Algeria in two crucial aspects: first, Tunisia transitioned to democracy in 2010 during the heady days of the Arab Spring. Second, Tunisia has never had access to the vast natural resources of its neighbor. We think that Algerians were quite likely to rely on comparisons to neighboring countries during their period of regime contention due to the well-known heuristics of availability bias (Weyland 2012).

In fact, it is quite plausible that if Algeria did not have access to oil-funded patronage in 2010, it might have transitioned to democracy as Tunisia did in 2011. As such, this counterfactual comparison is based on a potential path that Algeria could have explored in recent history. Benstead (2014) reports that Tunisia's struggles in the post-transition period influenced Algerians' perceptions of the strengths and weaknesses of democracy as a form of government, suggesting that Tunisia is the most relevant empirical model for Algerians when it comes to potential regime change. In fact, Ross (2012) uses Tunisia and Algeria to demonstrate how differences in oil endowments shape their remarkably different sizes of government despite the countries' similarities (pp. 29-30).

As such, we can use Tunisia as a empirically-grounded counterfactual for the taxation and representation trade-off: Tunisia has a much more representative and accountable government, but also a much higher tax burden for a similar level of social services. Tunisia can serve as a baseline for Algerians to evaluate the generosity of the benefits they obtain in exchange for continued authoritarianism. In other words, if Algeria did not have both oil and a ruler willing to share the wealth to an acceptable degree, it might look like Tunisia, a more democratic state with a higher tax burden. 
Of course, this comparison is only relevant to the extent that the theory itself holds. For example, it is quite plausible that Tunisia's transition to democracy and Algeria's authoritarianism had little to do with the former's lack of resources and the latter's abundance. If such a trade-off does not exist, then there is nothing stopping Algerians from deciding that they would prefer to receive their oil wealth under democracy regardless of the current regime type. However, if the trade-off does not exist, then informing Algerians about the nature of Tunisian public goods should result in null treatment effects and falsification of the rentier thesis that oil endowments diminish demands for representative government. If the rentier thesis does influence demands for democratization, then comparisons between oil-rich authoritarian countries and resource-poor democratic countries are a logical implication of the theory.

To make this comparison concrete, we designed two experimental comparative treatments based on three distinct policy regimes: gasoline subsidies, taxi rates and value-added taxes (VAT). As a petro state, Algeria passes on some of its hydrocarbon revenues to citizens by subsidizing gasoline, resulting in a divergence in gasoline prices between Algeria and Tunisia. ${ }^{6}$ Gasoline subsidies have previously been shown to be inimical to democratization (Fails 2019), suggesting they are an important mechanism besides tax burdens through which rentier largesse affects political calculations.

We include taxi fares as an alternative to gasoline subsidies in order to extend this treatment to cover Algerians who did not own cars. The difference in gasoline prices between Algeria and Tunisia should also result in differences in taxi prices, which affect most of the population. For this reason, our gas treatment uses either retail gasoline prices or taxi fare prices depending on whether the respondent owned a car. To estimate gasoline prices, we use historical gas pump prices for both countries. ${ }^{7}$ Estimating taxi prices is somewhat more difficult, though we are able to use crowd-sourced websites to come up with plausible average

6. In fact, gasoline smuggling is a lucrative occupation for residents of the mountainous Algerian-Tunisian border (Ghanem 2020).

7. See https://www.globalpetrolprices.com/Algeria/gasoline_prices/. 
rates of taxi fares for both countries. ${ }^{8}$

We chose to operationalize taxation in terms of indirect, value-added taxes because data on direct taxes, such as income taxation, is difficult to obtain and potentially of low quality, especially in Algeria. In addition, direct taxes represent only a small part of the taxation burden in much of the region (Jewell et al. 2015). For VAT rates, we can draw on helpful existing research of both nominal rates and total product coverage. Algeria's VAT rate of $19 \%$ is nominally the same as Tunisia's. However, the Algerian VAT is applied to far fewer goods according to research on VAT coverage rates by the IMF. ${ }^{9}$ As such, the effective VAT burden is far lower in Algeria than in Tunisia.

We then use these observed prices and VAT coverage rates to determine how much an individual might spend on gasoline, taxis or the VAT in Tunisia given a similar amount spent in Algeria. Table 1 shows these calculations for a hypothetical amount of 100 DZD spent in Algeria. A respondent will receive the gas treatment if they reported owning a car and a taxi treatment if they did not. We report these two treatments as one combined treatment in the results.

Table 1: Treatment Calculations

\begin{tabular}{lcc} 
Type & Amount Spent in Algeria & Counterfactual Spent in Tunisia \\
\hline Gasoline & 100 DZD & 200 DZD \\
Taxis & 100 DZD & 117 DZD \\
Spent on VAT & 3 DZD (for 100 DZD in Goods) & 7 DZD \\
\hline
\end{tabular}

As can be seen, hypothetical expenditures on both gas and goods covered by the VAT are roughly double what a person in Tunisia might pay relative to Algeria. Expenditures for taxis in Tunisia are not twice as high as in Algeria likely due to the fact that taxi rates are kept arbitrarily low in Tunisia, which has resulted in taxi driver protests in recent years. ${ }^{10}$ In any

8. See https://www.numbeo.com/taxi-fare/country_result.jsp?country=Algeria.

9. See https://www.imf.org/external/pubs/ft/sdn/2015/sdn1516.pdf.

10. For example, see https://arabtradeunion.org/en/tunisia-a-strike-for-the-individual-taxi-drivers-on-the-5th-of-november 
case, it is clear that the rentier state in Algeria does permit less taxation and a higher rate of subsidy of petrol relative to the less well-endowed Tunisia. We believe that this informationat least in this precise a form-would be relatively novel for Algerians and would provide an informative baseline for them to evaluate the amount that they are benefiting from the rentier state and whether that trade-off might justify continued authoritarianism.

The treatment text is as follows:

Based on what you entered, you paid [respondent amount] DZD for [gasoline/taxis/VAT goods] last year. If you lived in Tunisia, a democracy, where [gas/taxis/VAT] receives fewer subsidies, you would probably have spent [recalculated respondent amount] DZD on [gas/taxis/VAT].

The inclusion of the phrase, "a democracy," was an attempt to ensure that respondents would make the correct inference as to why Tunisia was the baseline for them to comparison with. However, out of concern that this suggestion would be too subtle, we also added the following text to $50 \%$ of the treatments:

However, Tunisia also has free and fair elections where people can hold politicians accountable.

This additional line of text provided some additional internal validity at the risk of some heavy-handedness. This treatment-within-treatment will help us understand if respondents' perceptions of the treatment is influenced by more subtle or more direct phrasing.

While these treatments provided information specific to individuals about their exposure to the rentier state, we also employed a treatment which contained general information about Algeria's oil resources. This treatment exploits the same counterfactual as that of the panel regressions mentioned earlier: over-time change in the amount of fuel earnings. If Algeria's dependence on oil revenues increases, then taxation makes us a smaller share of overall lang $=2$. 
government revenue. To capture this version of the treatment, we showed the following text to a subset of respondents:

For every 100 DZD the Algerian government collected in 2016, 34 DZD came from oil and the rest (66 DZD) came from people's taxes. Since then, however, the government has become ${ }^{*}$ more* reliant on oil for each 100 DZD it spends. By last year oil as a share of the government's money accounted for 40 DZD for every 100 DZD collected.

By comparison to the individual level treatments, this treatment examines how Algerians might respond to information about the overall state of their oil resources. It is likely that this information is relatively novel for respondents as it involves specifics about how much the Algerian government currently relies on oil resources. Theoretically, we would expect this information to have similar kind of effect to the individual treatments because it is showing that the government is obtaining more revenue from oil resources as opposed to other sources such as taxes.

As outcome measures, we consider both Algerians' attitudes towards their government and its provision of public goods, and also their willingness to take specific actions which could be interpreted as making representative demands in terms of regime change. We label the first set outcomes as governance measures, and the second as accountability measures. The first set of measures covers a wide set of criteria for evaluating the quality of Algeria's government, but is only probabilistically correlated with potential demands for representation. In other words, a respondent could reduce their perception of the government's performance without necessarily increasing representative demands, though we would expect a relationship to hold in the aggregate.

For this reason, we also include measures which more closely tap into the respondent's support for the regime. Because the Hirak had explicitly democratic goals such as for free and fair elections, we know that willingness to protest represents a relatively costly way of 
making demands for representation. While both sets of outcomes are relevant, the second set are much stronger tests of the taxation-representation thesis.

\section{Governance Measures}

Our governance measures come from the following survey question:

How would you rate the government's performance in these areas on a scale of 1 to 10 :

1 Providing employment for its citizens

2 Helping Algerians obtain health care and a quality education

3 Ending corruption among government officials

4 Reforming in response to citizens' concerns

5 Maintaining stability and social order

\section{Accountability Measures}

Our accountability measures come from the following survey question:

On a scale of 1 being very unlikely and 10 most likely, are how likely are you to take the following actions in the next 3 months:

1 Participate in a street protest

2 Visit a government official to complain about government services

3 Move personal funds to bank accounts overseas

4. Transfer funds from Algerian currency to other currencies

It is important to note that our actions include those which can unambiguously represent demands for more representation, i.e. joining street protests, and others that are somewhat more ambiguous. Transferring funds into and out of Algerian currency or moving money 
overseas can be a way of holding the regime accountable with one's own resources, though it does not necessarily mean that a respondent is trying to undermine the regime. Using multiple measures allows us to track the effect of the treatment across diverse ways of understanding confidence in the regime. The best measure, though, is willingness to join the protest movement.

All of the outcomes and experimental treatments were pre-registered, although the additional treatment text mentioned above was added after the pre-registration was filed. We also examine some treatment interactions, particularly with respondent wealth, which were not included in the pre-registration but which we believe to be crucial for understanding the aggregate results we report.

\section{Data}

Collecting survey responses in the midst of a national upheaval in a highly repressive authoritarian regime necessitates employing techniques that are more flexible than traditional face to face surveys. To do so, we recruited 5,968 Algerian residents from April to July 2019 via advertisements on Facebook. Facebook is by far the most popular social medium in the Middle East, used widely across age demographics and by official authorities (Dennis, Martin, and Wood 2016). Our advertisements, which asked for Algerians' opinions about the protests, attracted considerable attention, allowing us to recruit our nearly 6,000 respondent sample with a budget of only $\$ 5,000$, which included providing a 100 DZD mobile credit (approximately $\$ 0.75$ ) to all who finished the survey. ${ }^{11}$

Although the online design was both cost-effective and possible to field in a limited time frame, it was also necessary due to Algeria's heavy-handed restrictions on social science research, which have allowed very few surveys over the past several decades. In addition, online designs have an advantage in terms of safeguarding respondents' privacy, who can take

11. Not all respondents received a credit, either because they did not provide a mobile number or they did not provide a valid mobile number. 
the survey in secure locations, as well as reducing risks for enumerators who do not need to be on the ground. Aside from the voluntary collection of mobile numbers for reimbursement, the survey was anonymous, permitting more confidence in the safe and valid collection of opinions about Algerian politics. Online surveys have been shown to be better at collecting sensitive information (Chang and Krosnick 2010), reducing our concern over sensitive survey bias. In addition, political opinions and protest participation were not particularly sensitive during this time period in Algeria thanks to the constant presence of public protesters making radical demands against the regime (Kuran 1989).

Finally, we note that all of the information we provided in the experiment is truthful so far as available data permits. Because this information could influence Algerians' political actions, it is important that it provide them with accurate baselines about which to make decisions. While this information may have led some to participate in the protest movement, we note that the size of our sample means that it was unlikely to affect the success of the movement, which numbered in the hundreds of thousands. Furthermore, while we recorded the respondents' intentions to protest, we did not explicitly advocate for or against any political side in the survey.

The sample did not conform exactly to Algeria's population demographics, as can be seen in Table 2. The differences are most pronounced for age demographics, with overrepresentation in the under 30 groups and relatively few respondents over the age of 65 . On the other hand, we matched census totals for the total number employed and also for sex.

To adjust for potential bias, we implemented multiple regression with post-stratification (MRP), a powerful method utilized heavily in online survey research (Wang et al. 2014). To do so we constructed a contingency table of the population totals of Algerians by district, age and gender, and re-weighted our model predictions by each of the 864 cells in the contingency table. For this reason, we believe that we can plausibly interpret our estimates as being nationally representative along these three dimensions. The large size of our sample further allows us to be more confident that this method will work well. For example, even though 
only $2.5 \%$ of the sample is over the age of 55 , this subgroup still totals 131 respondents, giving us reasonable statistical power even for this older demographic.

Table 2: Comparison of Algerian Sample Demographics to Census Proportions

\begin{tabular}{lrr}
\hline Variable & Sample Proportion & Census Proportion \\
\hline Female & 48.7 & 49.6 \\
Male & 51.3 & 50.4 \\
$18-19$ & 10.5 & 1.2 \\
$20-24$ & 25.8 & 15.7 \\
$25-29$ & 20.2 & 14.2 \\
$30-34$ & 18.9 & 11.4 \\
$35-44$ & 16.0 & 18.1 \\
$45-54$ & 6.3 & 12.4 \\
$55-64$ & 2.1 & 7.4 \\
$65+$ & 0.3 & 7.6 \\
Rural & 15.4 & 31.9 \\
Suburban & 19.5 & $\mathrm{NA}$ \\
Urban & 65.1 & 68.1 \\
Employed & 36.2 & 37.4 \\
Housewife & 7.4 & $\mathrm{NA}$ \\
Retired & 2.7 & $\mathrm{NA}$ \\
Student & 30.6 & 10.0 \\
Unemployed & 23.0 & 10.5 \\
\hline
\end{tabular}

While much of the data is straightforward to analyze given that it was collected via an online instrument, we did need to perform additional validation to create a measure of socioeconomic resources (SES). To do so, we employed a latent variable model (Kubinec 2019) and collapsed a wide range of indicators of both income and wealth. We did so because, as is often the case with survey data, considerable measurement error exists in any single indicator, including monthly income. Furthermore, to understand how respondents may be affected by the rentier state, we need to know the respondents' overall level of resources rather than simply their current monthly income.

The inputs to our latent variable model included whether a respondent owned a car, a farm, a small, medium or large business; a house, whether they had a domestic or foreign 
$20000-$

$15000-$

¿ $10000-$

$5000-$

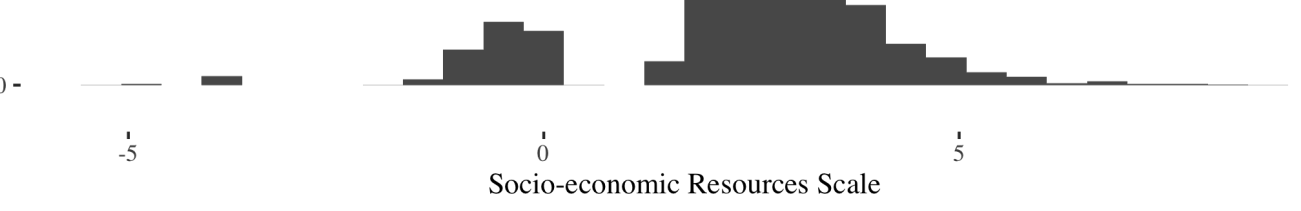

Figure 2: Histogram of SES Scale from Survey Data

bank account, sex, age, opinions about the state of the economy, level of education, a categorical measure of monthly income, the respondent's governorate, location (rural, urban or suburban), and also the amounts respondents reported spending on fuel, taxis and VAT goods in the experimental treatments. Combining all of these with appropriate statistical distributions and employing a two-stage correction for non-ignorable missing data (Kubinec 2019), we then estimated an SES scale which is shown in Figure 2. Although the scale is continuous, it shows discrete breaks due to the fact that categorical variables with a strong effect on SES (ownership of homes or businesses) were included in estimation. The full list of discrimination parameters (i.e., factor scores) for all covariates in the SES scale is shown in Figure 2 in the appendix.

It is important to note that the SES scale is a latent variable, and as such it does not need to follow a power law distribution like reported income. Rather, it is useful for making 
relative comparisons between respondents in terms of their wealth position rather than the absolute amount of income or they possess. We do note that relatively few of the respondents are either very poor or very rich (scores above or below $+/-5$ ), with the majority reporting at least some income or other source of support.

\section{Results}

We first report the average treatment effects (ATEs) for each treatment group in Figures 3 and 4. The taxi and gas treatments are combined into one treatment result labeled fuel subsidy, while the change in oil revenues treatment is listed separately. To calculate ATEs adjusted with MRP, we first estimate predicted average values from the 0 to 10 scales used to evaluate either the respondent's attitude towards the government or the respondent's likelihood of engaging in a certain type of behavior for both treatment and control. These predictions were then adjusted using the Algerian census data with MRP as discussed previously, and as such are plausibly representative of the population, at least in terms of the distribution of gender, age and sex by district. To obtain an ATE, we then subtracted the treatment average predicted value from the control average predicted value.

As can be seen, the adjusted ATEs for governance outcomes in Figure 3 show that receiving information about an individual's tax burden, relative level of fuel subsidies or government's increasing reliance on oil revenues causes an increase on average among our respondents in terms of improved perceptions of the government's performance. The effect is quite stable, of medium strength (roughly +0.3 to +0.5 on a scale of 0 to 10 ), and holds true for the three different types of treatments.

By comparison, the predicted ATEs for the accountability outcomes show much lower movement. Only for one outcome, complaining to a government official, do we see statisti-

cally significant differences, and these are also smaller than the governance effects (approximately +0.2 to +0.3$)$. For the other outcomes, confidence intervals indicate few differences 

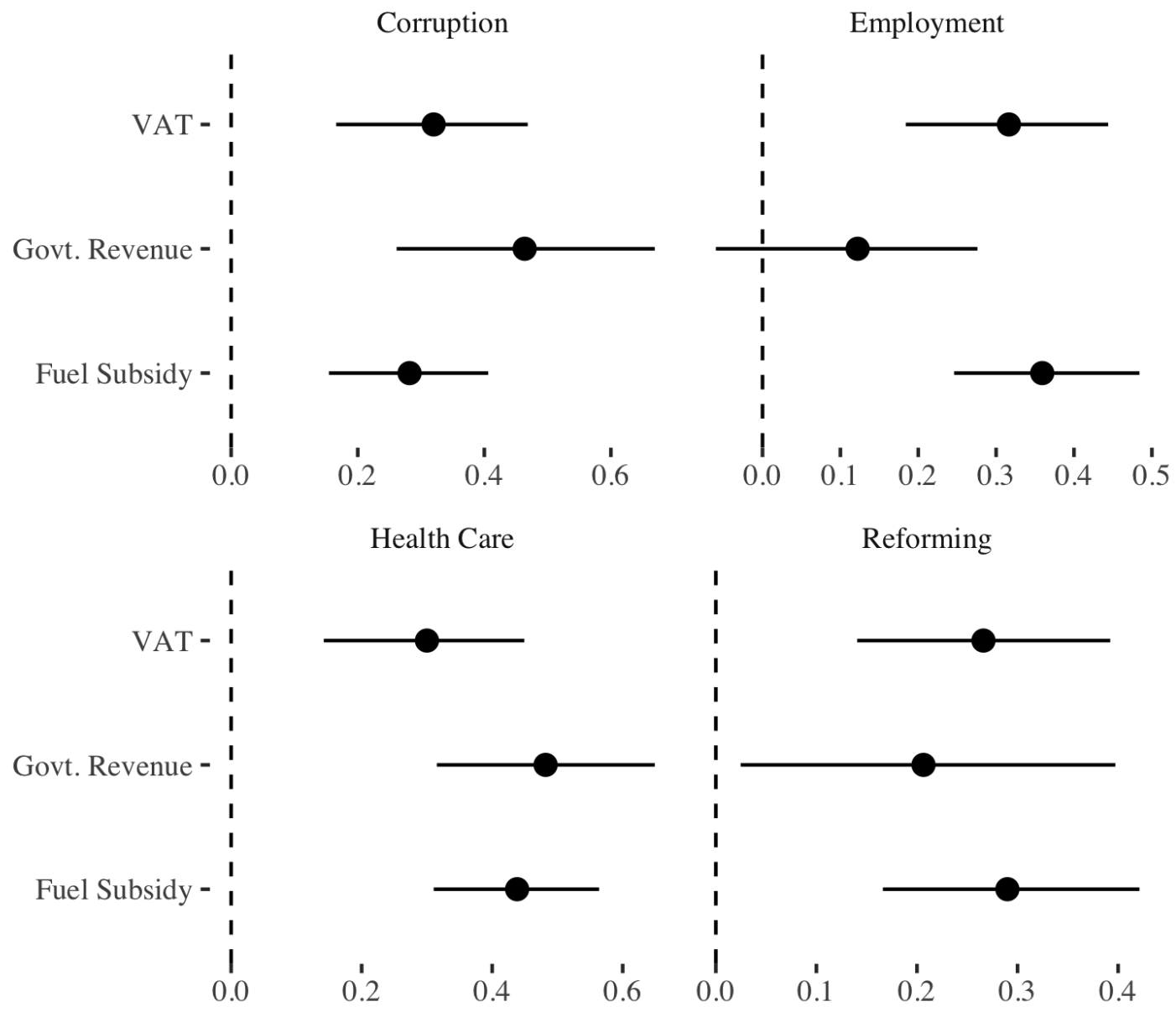

Stability

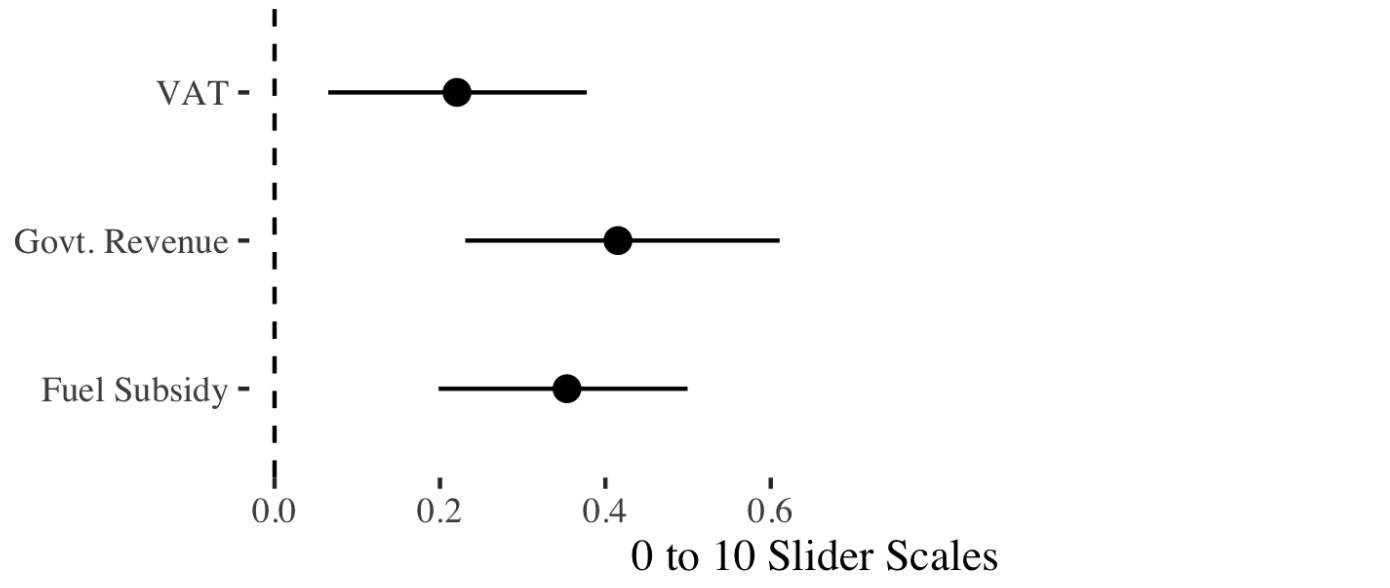

Estimates are the difference of the predicted values of the $0-10$ outcome assessing the government's performance between treatment and control. Estimates are adjusted with MRP to match Algerian census totals.

Figure 3: Predicted Values (ATEs) by Governance Outcome, Adjusted with MRP 

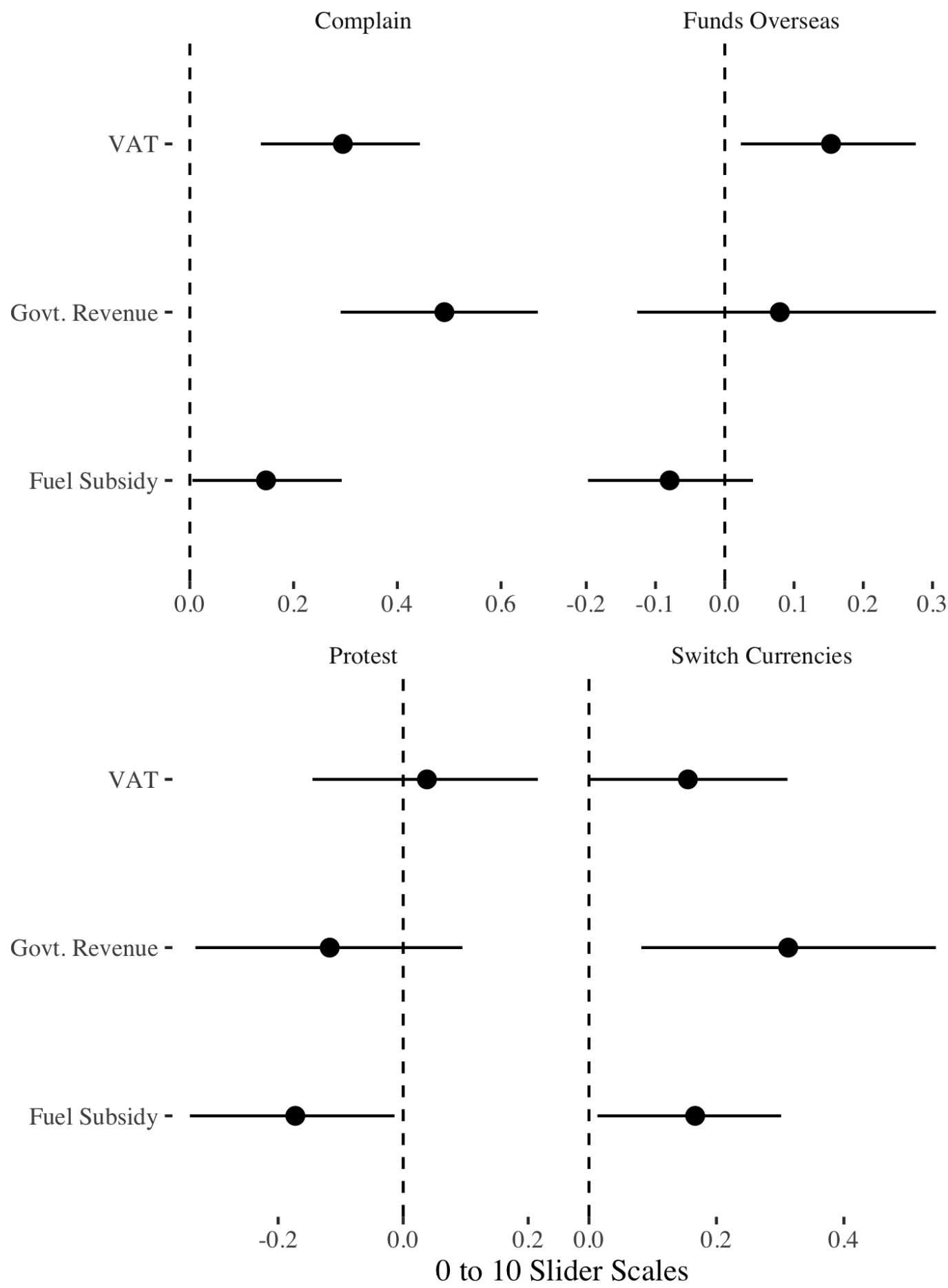

Estimates are the difference of the predicted values of the $0-10$ outcome assessing the government's performance between treatment and control. Estimates are adjusted with MRP to match Algerian census totals.

Figure 4: Predicted Values (ATEs) by Accountability Outcomes, Adjusted with MRP 
which suggest meaningful treatment effects. As such, our sample average results only show movement for governance measures, which are an imperfect measure of demands for representation, and only moderate effects in one of our accountability measures. We do not see any movement in the protest outcome, which as noted earlier, is our best measure of demands for representation.

In the appendix we report the treatment interactions with the additional text incorporated about Tunisia's free and fair elections. These results do not show any noticeable increase or decrease in treatment effectiveness, suggesting that the simpler wording was able to communicate the nature of the trade-off we wanted respondents to make between Algeria and Tunisia.

\section{Wealth as a Moderator}

However, as we noted earlier, the effect of our treatment should be conditional on a respondent's socio-economic resources. Averaging over the income distribution, as our previous set of results do, is not the most informative way of estimating the impact of the rentier state on individuals' demands for representation. Greater wealth could indicate more significant benefits from the welfare state in exchange for a proportionally greater decrease in taxation. For this reason, we interact each treatment with the SES scale we explicated previously, and we show the results for this interaction in Figure 5 for the governance outcomes and Figure 6 for the outcomes. Due to the large number of treatments and outcomes, each plot shows a comparison between the predicted outcome for control and one treatment group across values of the SES scale. As with the sample average effects, these results are also adjusted with MRP for population representativeness.

These interactions reveal important treatment heterogeneity for the governance outcomes in Figure 5 that is masked by the sample average effects. While there are differences in size and strength across treatments, the treatment effect of encouraging stronger perceptions of the government's performance is concentrated among the wealthy. Among poorer respon- 


\section{Treatments}

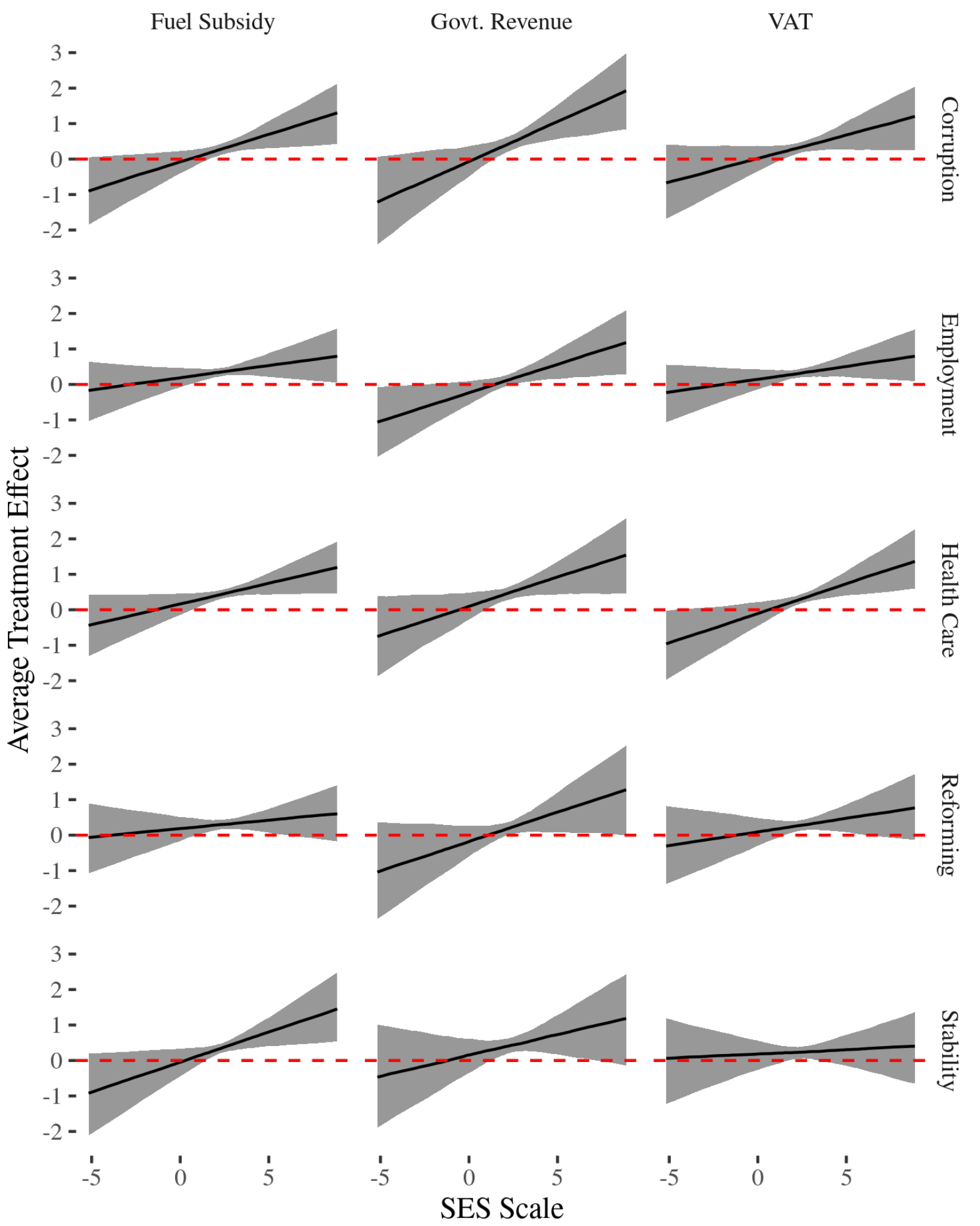

Estimates are the difference of the predicted values of the $0-10$ outcome assessing the government's performance between treatment and control. Estimates are adjusted with MRP to match Algerian census totals.

Figure 5: Predicted Values (ATEs) Conditioned by SES Scale, Governance Outcomes 
dents, providing the treatment either had a null effect or even a negative effect on their attitudes towards governance. It is interesting as well that the lines in Figure 5 all slope upwards, i.e., the wealthy almost always have a more positive response to the treatment than the poor.

Figure 6 shows the same patterns as Figure 5, though treatment heterogeneity is strongest for protest intentions. Very poor respondents tended to report much higher willingness to protest following the receipt of information, indicating they were not particularly impressed with the government's generosity, while the wealthy became much less willing to protest. The effect is sizable and reaches nearly -2 points on the scale for the fuel subsidy and VAT treatments among the top end of the income distribution. We do not observe as strong divergences for less directly political outcomes such as moving funds overseas or switching currencies, though again when a relationship can be identified, it shows that the wealthy are less likely to take actions which indicate lower confidence in the regime such as switching currencies.

\section{Opinion about Protests as a Moderator}

While we believe that SES is the most theoretically relevant treatment moderator, we look at other potential moderators to provide context for these findings. We first examine possible treatment heterogeneity by the preferences that respondents held about the Hirak movement before observing the treatment. Figures 7 and 8 show the governance and accountability results respectively for the treatments by subgroups defined by respondents' answers to the question, "do you support or oppose the goals of the current wave of protests in Algeria?" As is evident, there are more respondents who reported supporting the protests, and as such those categories have more precise estimates.

On the whole, the results show that opinion about protests has a moderating effect on governance but not accountability, at least in general. The governance results show that the positive effects on governance hold for those who support the protests; i.e., their views of 


\section{Treatments}

Fuel Subsidy Govt. Revenue $\quad$ VAT

$5.0-$

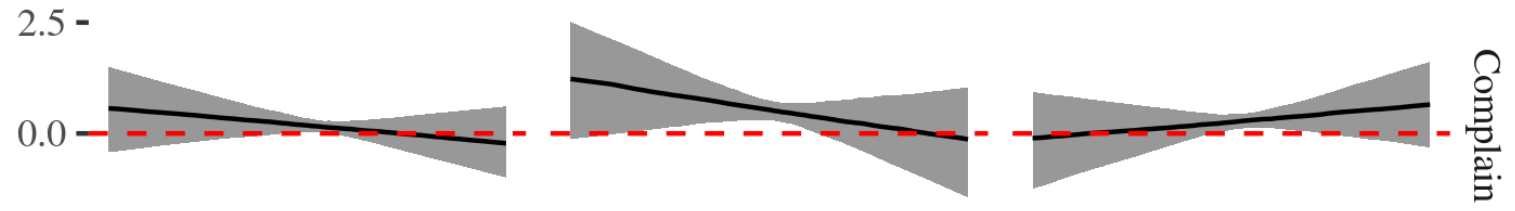

$-2.5-$

$5.0-$
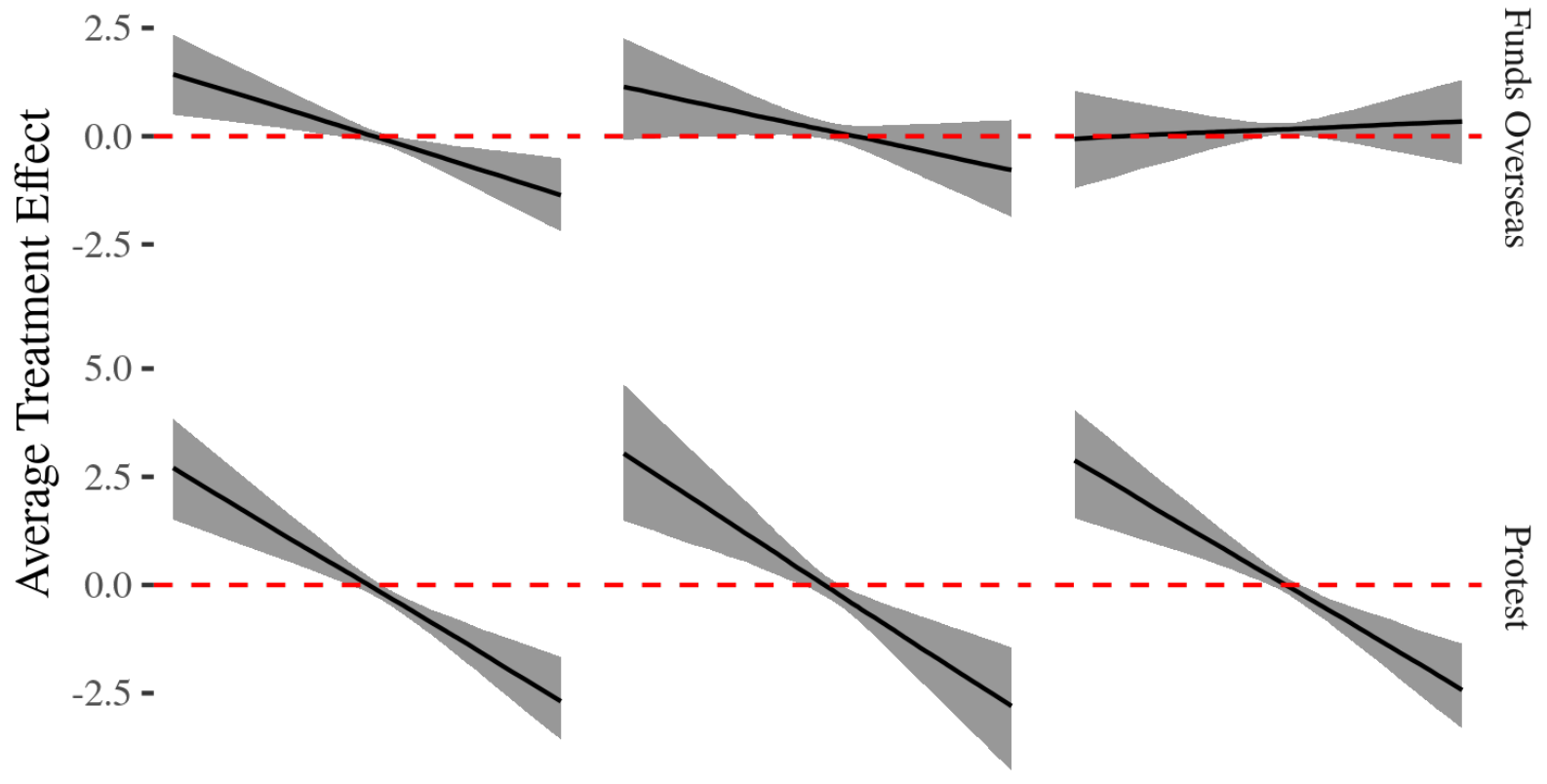

$5.0-$

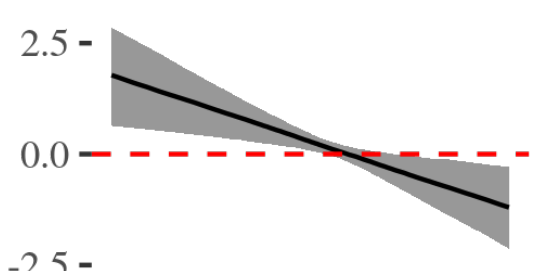

$-2.5-$

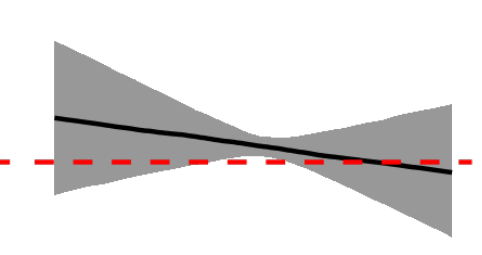

$-$
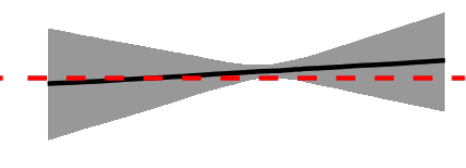

$\begin{array}{lll}1 & 1 & 1 \\ -5 & 0 & 5\end{array}$

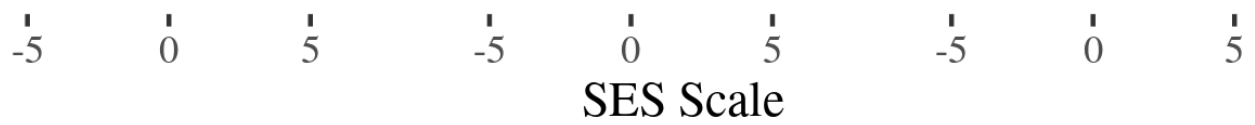

Estimates are the difference of the predicted values of the $0-10$ outcome assessing the government's performance between treatment and control. Estimates are adjusted with MRP to match Algerian census totals.

Figure 6: Predicted Values (ATEs) Conditioged by SES Scale, Accountability Outcomes 


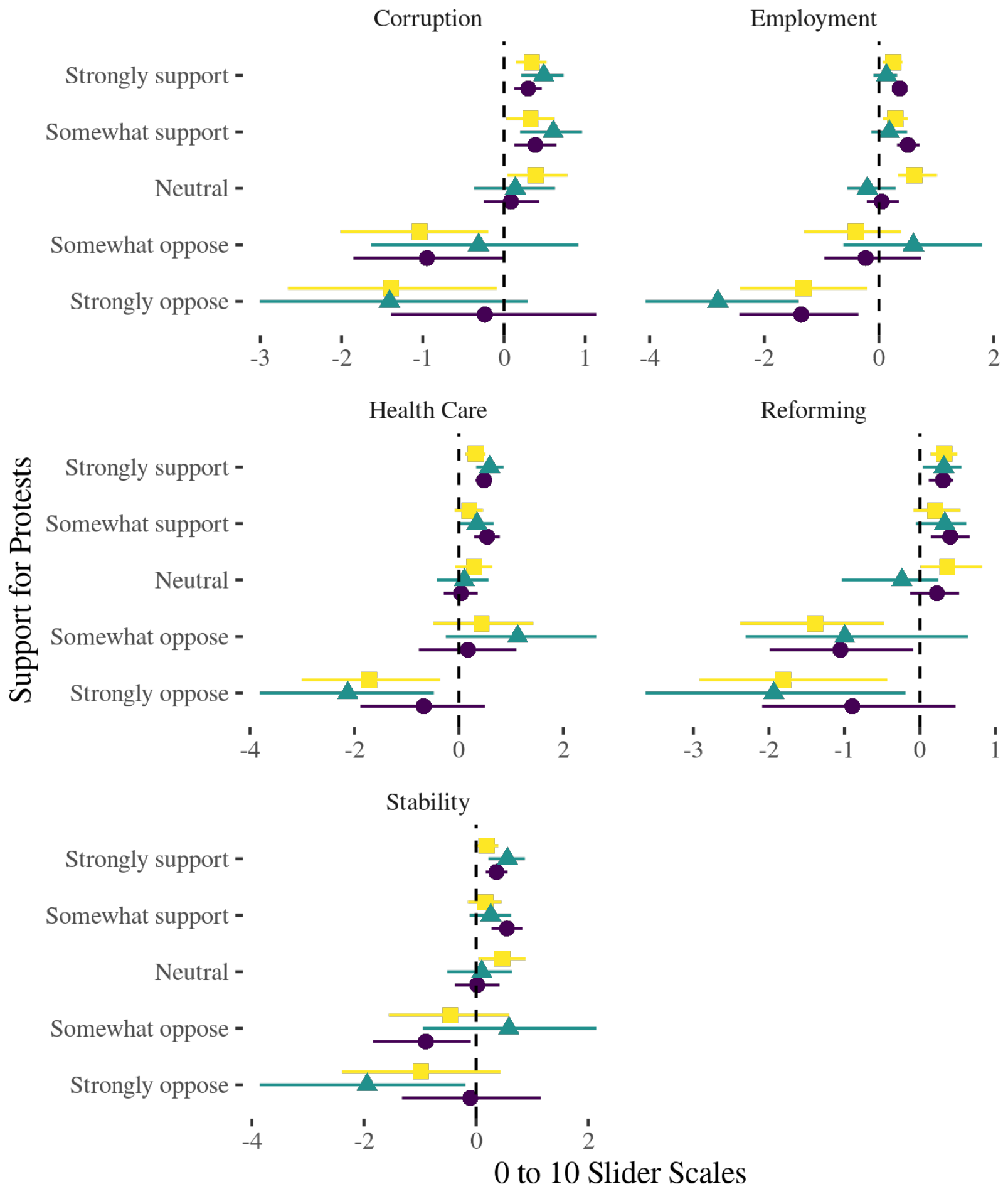

Treatment $\phi$ Fuel Subsidy $\quad \uparrow$ Govt. Revenue $\frac{\phi}{4}$ VAT

Estimates are differences in the $0-10$ outcome assessing the government's performance between treatment and control. Estimates are adjusted with MRP to match Algerian census totals.

Figure 7: ATEs Conditioned by OpiniongAbout Protests, Governance Outcomes 


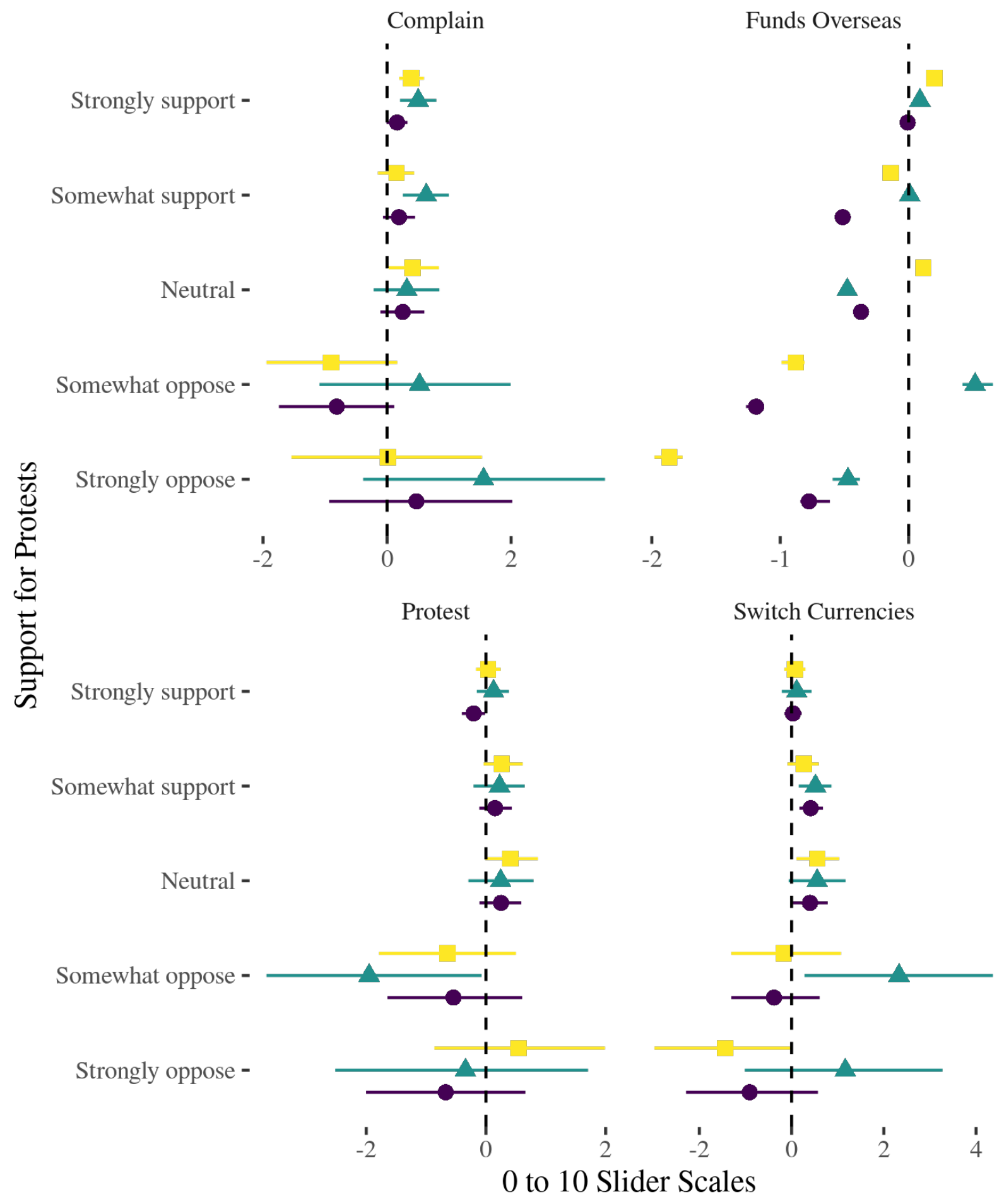

Treatment $\phi$ Fuel Subsidy $\quad$ 个 Govt. Revenue $\phi$ VAT

Estimates are differences the 0-10 outcome of the likelihood of a given action between treatment and control. Estimates are adjusted with MRP to match Algerian census totals.

Figure 8: ATEs Conditioned by Opinion 3 bout Protests, Accountability Outcomes 
the government's performance increase approximately +0.2 to +0.5 on average. By contrast, those who oppose the protests show negative effects in response to the treatment; however, it is somewhat difficult to make firm conclusions as the effects are imprecisely estimated. For accountability measures, there do not appear to be clear patterns other than for the outcome of moving funds overseas. Those who opposed the protests were much less likely, between -1 and -2 points, to report wanting to move funds overseas. While intriguing, and fairly precisely estimated, it is difficult to comment on this particular finding as the other subgroups do not show clear patterns across protest opinion.

\section{Opinion about Corruption as a Moderator}

Next we examine beliefs about corruption in the government as a potential moderator of the treatment. We examine respondent opinions about corruption because it is an important factor in how respondents might evaluate the rentier state: if they believe the rentier state is less corrupt, they may also assess its redistributive performance more positively. Figures 9 and 10 show the results for governance and accountability outcomes respectively subset by respondents' opinions about the level of corruption in government (question: "In your opinion, what is the level of corruption among government officials in Algeria today?"). In a similar pattern to the protest support moderator, those who believe that corruption is quite high show stronger effects from the treatment for governance outcomes. Again, there do not appear to be very clear patterns for the accountability outcomes, with substantial variability across treatments within outcomes.

\section{Discussion}

When we examine treatment moderation using our SES scale, it is clear that the treatment is powerfully conditioned by wealth. Those at the top end of the wealth distribution were considerably less likely (two to three points out of a 10-point scale) to report a willingness 


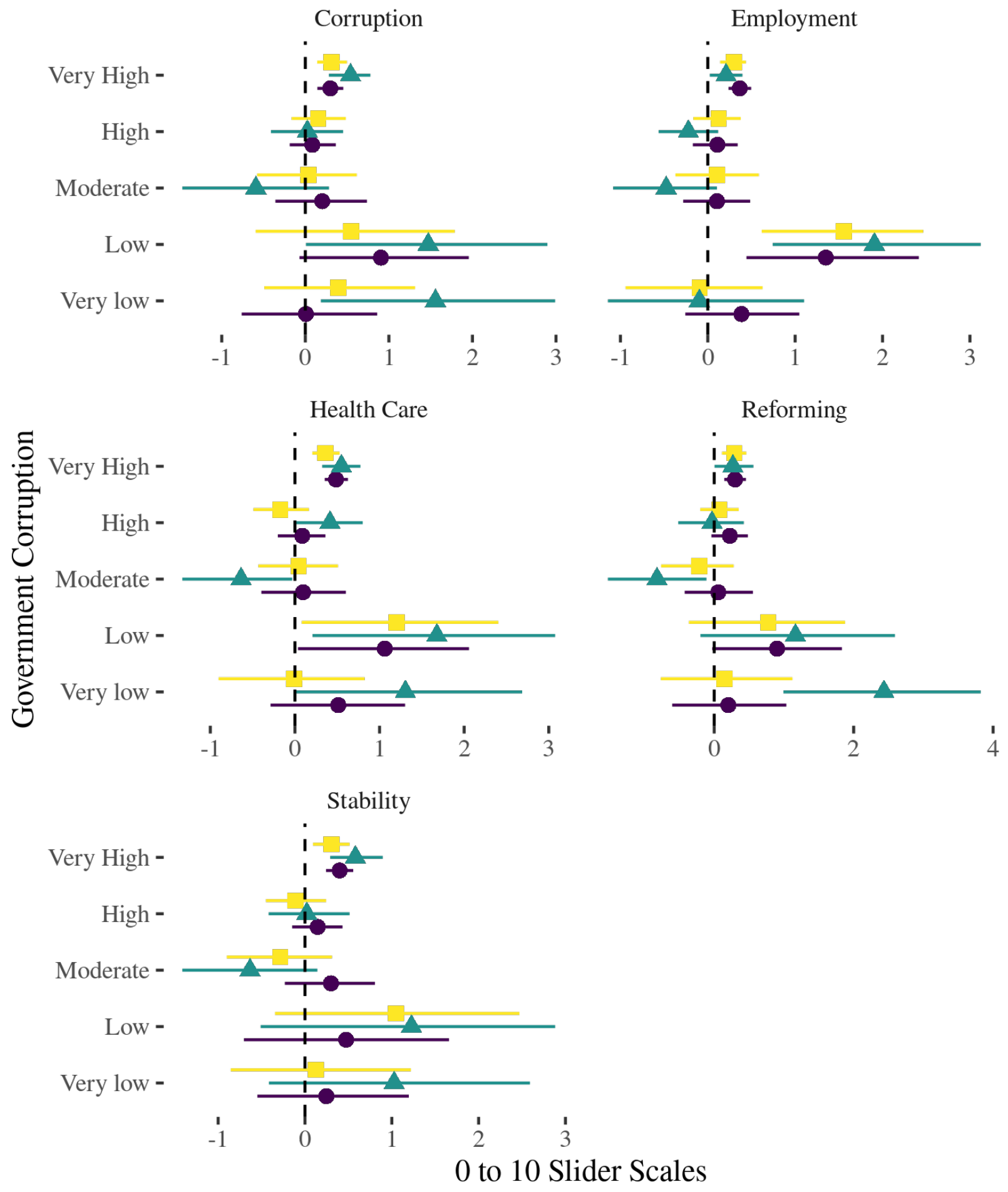

\section{Treatment $\phi$ Fuel Subsidy $\quad \uparrow$ Govt. Revenue $\downarrow$ VAT}

Estimates are differneces in the 0-10 outcome assessing the government's performance between treatment and control. Estimates are adjusted with MRP to match Algerian census totals.

Figure 9: ATEs Conditioned by Opinion Abgat Government Corruption, Governance Outcomes 


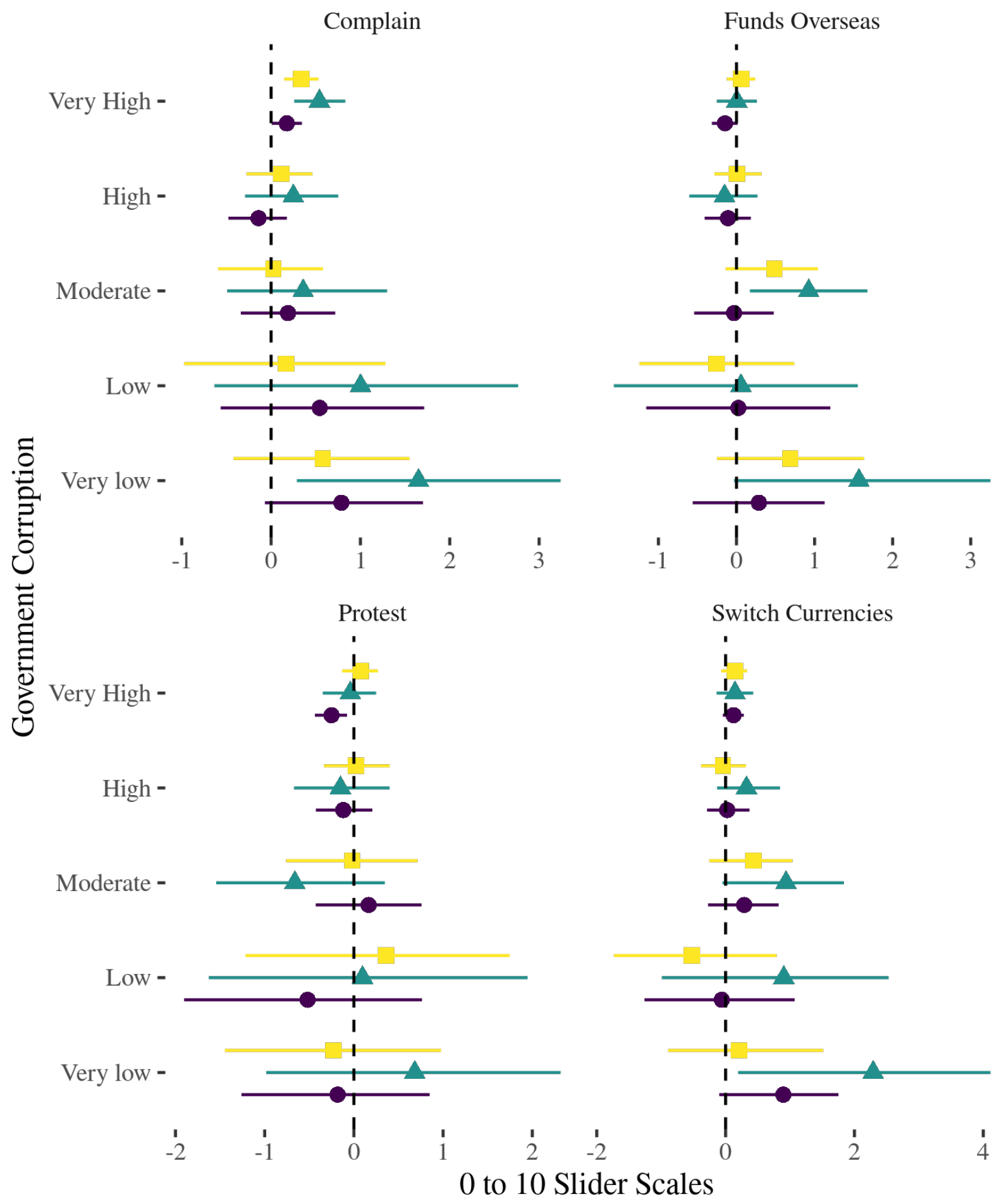

\section{Treatment $\phi$ Fuel Subsidy $\quad+$ Govt. Revenue + VAT}

Estimates are differences in the 0-10 outcome assessing the likelihood of taking a particular between treatment and control. Estimates are adjusted with MRP to match Algerian census totals.

Figure 10: ATEs Conditioned by Opinion Aggout Government Corruption, Accountability Outcomes 
to protest after receiving a treatment, while those at the bottom of the distribution became more likely to protest after receiving the treatment. These conditional effects also hold for governance outcomes and also some other accountability measures (movement of funds overseas).

These results follow from a framework in which rulers are trying to mitigate threats to their rule but face varying challenges from the elites and the masses. In terms of threats from below, if inequality increases and the rich are able to capture the lion's share of the rentier state's public goods, then the willingness of the poor to engage in costly mobilization to oppose the regime also rises (Acemoğlu and J. Robinson 2006; Boix 2003). Similarly, as Dunning (2008) shows, the rentier state can help mitigate private sector inequality, but only if public goods represent true redistribution to the poor. For these reasons, to avoid popular mobilization, rulers should try to make the rentier state as inclusive as possible, which Algeria was able to do during the earlier Arab Spring protest movement in 2011 by dispensing subsidies targeted at consumers.

However, rulers also need to keep elites co-opted, who often represent a more immediate threat in terms of regime survival (Gehlbach and Keefer 2011; Marinov and Goemans 2014; Ansell and Samuels 2014). In fact, Geddes, Wright, and Frantz (2014) show that oil has its greatest effect on authoritarian durability by avoiding coups from rival factions. Popular mobilization, by contrast, is relatively rare and can also be contained with repression (Bellin 2004). As a result, it could be a natural outcome that over time rentier states become more elite-biased as political coalitions evolve and rulers aim to maximize their longevity (Waterbury 1983; Waldner 1999; Haber, Razo, and Maurer 2003; Acemoğlu and J. A. Robinson 2008). As a consequence, a redistributive policy favoring elites could be optimal from the perspective of a given leader, but suboptimal for the long-term survival of the regime if it eventually leads to counter-regime mobilization among the poor. 


\section{Conclusion}

As can be expected, our granular data combined with a causally-identified research design both answers questions and raises others. We are able to show that increasing Algerians' information about the extent of the rentier state relative to neighboring countries does improve their perception of regime performance. As such, these experimental results suggest that core parts of the rentier theory concerning the bargain that citizens make with an au-

thoritarian regime do have merit. At the same time, strong heterogeneity across politically salient divides-especially in terms of class-suggest that in times of popular mobilization, perceptions of the rentier state are far from uniform. Our treatment seems to have produced a backlash effect among poorer Algerians, substantially increasing their reported willingness to engage in protest activity after being informed about the extent of the rentier state.

These results point to the inclusivity of the rentier state as a critical variable underpinning its effectiveness at containing protest. Even if the state remains in regional perspective a credible provider of public goods, the relative share of public good provision for the poor versus the rich may still be an issue of contention. If Algerians come to the conclusion that the rentier state is biased in favor of the rich and powerful, it is difficult to overcome that grievance solely through general reminders of the extent of redistribution. Under what conditions regime elites are able to manage this difficult trade-off between elite concerns and mass unrest is an interesting question for future research.

\section{References}

Acemoğlu, Daron, and James Robinson. 2006. Economic origins of dictatorship and democracy. Cambridge University Press.

Acemoğlu, Daron, and James A Robinson. 2008. "Persistence of power, elites, and institutions." American Economic Review 98 (1): 267-93. 
Achy, Lahcen. 2012. Algeria Avoids the Arab Spring? Carnegie Middle East Center, May 31, 2012. Accessed April 18, 2022. https://carnegie-mec.org/2012/05/31/algeria-avoidsarab-spring-pub- 48277.

Andersen, Jorgen J., and Michael L. Ross. 2014. "The big oil change: A closer look at the haber-menaldo analys." Comparative Political Studies 47 (7): 993-1021.

Anderson, Lisa. 1987. "The State in the Middle East and North Africa." Comparative Politics 20 (1): 1-18. ISSN: 0010-4159, accessed December 5, 2021. https://doi.org/10.2307/ 421917. https://www.jstor.org/stable/421917.

Ansell, Ben W., and David J. Samuels. 2014. Inequality and democratization: An elitecompetition approach. Cambridge, UK: Cambridge University Press.

Ayubi, Nazih. 1995. Over-stating the arab state: Politics and society in the middle east. I.B. Tauris.

Beblawi, Hazem, and Giacomo Luciani, eds. 1987. The rentier state. Croom Helm Ltd.

Bellin, Eva. 2004. "The robustness of authoritarianism in the middle east: Exceptionalism in comparative perspective." Comparative Politics 36, no. 2 (January): 139-157.

Benstead, Lindsay. 2014. "Why some Arabs don’t want democracy." Washington Post (September 30, 2014). ISSN: 0190-8286, accessed April 26, 2022. https://www.washingtonpost. com/news/monkey-cage/wp/2014/09/30/why-some-arabs-dont-want-democracy/.

Boix, Carles. 2003. Democracy and redistribution. Cambridge University Press. 
Brooks, Sarah M., and Marcus J. Kurtz. 2016. "Oil and Democracy: Endogenous Natural Resources and the Political "Resource Curse"" Publisher: Cambridge University Press, International Organization 70 (2): 279-311. ISSN: 0020-8183, 1531-5088, accessed April 20, 2022. https://doi.org/10.1017/S0020818316000072. https://www.cambridge.org/core/ journals / international- organization / article / oil- and-democracy- endogenous- naturalresources-and-the-political-resource-curse/1770E911751F65F42C8BE1BAF7BFC491.

Brownlee, Jason, Tarek Masoud, and Andrew Reynolds. 2015. The arab spring: Pathways of repression and reform. Oxford University Press.

Chang, Linchiat, and Jon A. Krosnick. 2010. "Comparing oral interviews with self-administered computerized questionnaires: An experiment." Public Opinion Quarterly 74 (1): 154167.

Corden, W. M. 1984. "Booming Sector and Dutch Disease Economics: Survey and Consolidation." Oxford Economic Papers 36 (3): 359-380. ISSN: 0030-7653, accessed July 20, 2021. https://www.jstor.org/stable/2662669.

Crystal, Jill. 1990. Oil and Politics in the Gulf: Rulers and Merchants in Kuwait and Qatar. Cambridge Middle East Library. Cambridge: Cambridge University Press. IsBn: 978-0521-46635-6, accessed December 6, 2021. https://doi.org/10.1017/CBO9780511558818. https://www.cambridge.org/core/books/oil-and-politics-in-the-gulf/CDE9790AAD2C D2940DC6AA4AC7639CE2.

Cuesta, Brandon de la, Helen V. Milner, Daniel L. Nielson, and Stephen F. Knack. 2019. "Oil and aid revenue produce equal demands for accountability as taxes in Ghana and Uganda." Proceedings of the National Academy of Sciences 116, no. 36 (September 3, 2019): 17717-17722. 
De La O, Ana L. 2013. "Do Conditional Cash Transfers Affect Electoral Behavior? Evidence from a Randomized Experiment in Mexico." American Journal of Political Science 57 (1): 1-14. ISSN: 0092-5853, accessed December 20, 2021. https://www.jstor.org/stable/ 23496539 .

Dennis, Everette E., Justin D. Martin, and Robb Wood. 2016. Media use in the middle east. Interactive report. Northwestern University in Qatar. http://www.mideastmedia.org/.

Dillman, Bradford. 2000. State and private sector in algeria: The politics of rent-seeking and failed development. Westview Press.

Dincecco, Mark. 2009. "Fiscal Centralization, Limited Government, and Public Revenues in Europe, 1650-1913." The Journal of Economic History 69, no. 1 (March): 48-103. ISSN: 1471-6372, 0022-0507, accessed May 4, 2021. https://doi.org / 10 . 1017 / S002 2050709000345. https : / / www . cambridge . org / core / journals / journal - of - economichistory / article/abs / fiscal-centralization-limited-government- and-public-revenues-ineurope-16501913/69CBC2A1CD3B166E445FBE2960A59328.

Diwan, Ishac. 2013. "Understanding Revolution in the Middle East: The Central Role of the Middle Class." Publisher: Routledge _eprint: https://doi.org/10.1142/S1793812013500041, Middle East Development Journal 5, no. 1 (January 1, 2013): 1350004-1-1350004-30. ISSN: 1793-8120, accessed April 26, 2022. https://doi.org/10.1142/S1793812013500041. https://doi.org/10.1142/S1793812013500041.

Dunning, Thad. 2008. Crude democracy: Natural resource wealth and political regimes. Cambridge, UK: Cambridge University Press.

Fails, Matthew D. 2019. "Fuel Subsidies Limit Democratization: Evidence from a Global Sample, 1990-2014." International Studies Quarterly 63, no. 2 (June 1, 2019): 354363. ISSN: 0020-8833, accessed June 28, 2021. https://doi.org/10.1093/isq/sqy061. https://doi.org/10.1093/isq/sqy061. 
Fjelde, Hanne. 2009. "Buying Peace? Oil Wealth, Corruption and Civil War, 1985-99." Journal of Peace Research 46, no. 2 (March 1, 2009): 199-218. ISSN: 0022-3433, accessed July 20, 2021. https://doi.org/10.1177/0022343308100715. https://doi.org/10.1177/ 0022343308100715.

Gadenne, Lucie. 2017. "Tax Me, but Spend Wisely? Sources of Public Finance and Government Accountability." American Economic Journal: Applied Economics 9 (1): 274-314. ISSN: 1945-7782, accessed June 28, 2021. https://www.jstor.org/stable/26156215.

Gandhi, Jennifer. 2008. Political institutions under dictatorships. Cambridge University Press.

Geddes, Barbara, Joseph Wright, and Erica Frantz. 2014. "Autocratic breakdown and regime transitions: A new data set." Perspectives on Politics 12 (2): 313-331.

Gehlbach, Scott, and Philip Keefer. 2011. "Investment without democracy: Ruling-party institutionalization and credible commitment in autocracies." Journal of Comparative Economics 39 (2): 123-139.

Ghanem, Dalia. 2020. "Algeria's Borderlands: A Country Unto Themselves." Carnegie Middle East Center, July. Accessed April 27, 2022. https://carnegie-mec.org/2020/05/27/ algeria-s-borderlands-country-unto-themselves-pub- 81881 .

Grewal, Sharan. 2021. "Why Sudan Succeeded Where Algeria Failed." Publisher: Johns Hopkins University Press, Journal of Democracy 32 (4): 102-114. ISSN: 1086-3214, accessed April 26, 2022. https://doi.org/10.1353/jod.2021.0055. https://muse.jhu.edu/article/ 815940.

Grewal, Sharan, Tahir Kilavuz, and Robert Kubinec. 2019. Algeria's uprising: A survey of protesters and the military. Brookings Institution, July 15, 2019. Accessed April 8, 2021. https: / / www . brookings. edu / research / algerias- uprising-a-survey- of - protesters- andthe-military/. 
Haber, Stephen, Armando Razo, and Noel Maurer. 2003. The politics of property rights: Political instability, credible commitments, and economic growth in mexico, 1876-1929. Cambridge University Press.

Haggard, Stephan, and Robert R Kaufman. 2012. "Inequality and regime change: Democratic transitions and the stability of democratic rule." American Political Science Review 1 (1): $1-22$.

Herb, Michael. 2005. "No representation without taxation? Rents, development and democracy." Comparative Politics 27 (3): 297-316.

Houle, Christian. 2018. "A two-step theory and test of the oil curse: the conditional effect of oil on democratization." Publisher: Routledge _eprint: https://doi.org/10.1080/13510347.2017.1366449 Democratization 25, no. 3 (April 3, 2018): 404-421. ISSN: 1351-0347, accessed April 20, 2022. https://doi.org/10.1080/13510347.2017.1366449. https://doi.org/10.1080/ 13510347.2017.1366449.

Jamal, Amaney, and Mark Tessler. 2008. "The Democracy Barometers (Part II): Attitudes in the Arab World." Journal of Democracy 19 (1): 97-111. ISSN: 1086-3214, accessed March 15, 2021. https://doi.org/10.1353/jod.2008.0004. https://muse.jhu.edu/article/ 230461.

Jewell, Andrew, Mario Mansour, Pritha Mitra, and Carlo Sdralevich. 2015. Fair Taxation in the Middle East and North Africa. Staff Discussion Notes. International Monetary Fund, September. Accessed April 20, 2022. https://www.imf.org/external/pubs/ft/ $\operatorname{sdn} / 2015 / \operatorname{sdn} 1516 . p d f$.

Jones, Calvert W. 2017. Bedouins into Bourgeois: Remaking Citizens for Globalization. Cambridge: Cambridge University Press. ISBN: 978-1-107-17572-3, accessed July 20, 2021. https:// doi.org/10.1017/9781316800010. https://www.cambridge.org/core/books / bedouins-into-bourgeois/E13C0A33D662B6EF9E4B3FC7FCC31547. 
Karl, Terry Lynn. 1997. The Paradox of Plenty. University of California Press, December 31, 1997. ISBN: 978-0-520-91869-6, accessed July 20, 2021. https://www.degruyter.com/ document/doi/10.1525/9780520918696/html.

Ketchley, Neil, and Christopher Barrie. 2020. "TRENDS: Fridays of Revolution: Focal Days and Mass Protest in Egypt and Tunisia." Publisher: SAGE Publications Inc, Political Research Quarterly 73, no. 2 (June 1, 2020): 308-324. ISSN: 1065-9129, accessed April 26, 2022. https://doi.org/10.1177/1065912919893463. https://doi.org/10.1177/1065912919 893463.

King, Gary. 1997. A Solution to the Ecological Inference Problem. Princeton University Press, April 6, 1997. ISBN: 978-0-691-01240-7, accessed December 20, 2021. https://press.pr inceton.edu/books / paperback/9780691012407/a-solution-to-the-ecological-inferenceproblem.

Kubinec, Robert. 2019. "Generalized ideal point models for time-varying and missing-data inference." Open Science Foundation Preprints, https://doi.org/10.31219/osf.io/8j2bt.

Kuran, Timur. 1989. "Sparks and prairie fires: A theory of unanticipated political revolution." Public Choice 61 (1): 41-74.

Levi, Margaret. 1989. Of rule and revenue. Berkely, CA: University of California Press.

Magaloni, Beatriz, and Ruth Kricheli. 2010. "Political order and one-party rule." Annual Review of Political Science 13, no. 1 (May): 123-143. https://doi.org/10.1146/annurev. polisci.031908.220529. http://dx.doi.org/10.1146/annurev.polisci.031908.220529.

Mahdavy, Hossein. 1970. "Patterns and Problems of Economic Development in Rentier States : the Case of Iran." In Studies in the Economic History of the Middle East. Routledge. ISBN: 978-1-315-00031-2. 
Malik, Adeel, Izak Atiyas, and Ishac Diwan. 2020. "Introduction." In Crony capitalism in the middle east: Business and politics from liberalization to the arab spring. Oxford Univeristy Press.

Marinov, Nikolay, and Hein Goemans. 2014. "Coups and democracy." British Journal of Political Science 44 (4): 799-825.

Marwane, Ahmed. 2021. After Two Years of Algeria's Hirak, What Has Been Accomplished? The Washington Institute, March 31, 2021. Accessed December 20, 2021. https://www. washingtoninstitute.org/policy-analysis/after-two-years-algerias-hirak-what-has-beenaccomplished.

Migdal, Joel S. 1988. Strong societies and weak states: State-society relations and state capabilities in the third world. Princeton: Princeton University Press.

Paler, Laura. 2013. "Keeping the Public Purse: An Experiment in Windfalls, Taxes, and the Incentives to Restrain Government." American Political Science Review 107, no. 4 (November): 706-725. ISSN: 0003-0554, 1537-5943, accessed June 28, 2021. https: //doi.org/10.1017/S0003055413000415. https://www.cambridge.org/core/journals / american-political-science-review/article/keeping-the-public-purse-an-experiment-inwindfalls-taxes-and-the-incentives-to-restrain-government/1015EC29926C5ADD82C1 4FFECC582A4D.

Prichard, Wilson. 2015. Taxation, Responsiveness and Accountability in Sub-Saharan Africa: The Dynamics of Tax Bargaining. Cambridge: Cambridge University Press. ISBN: 9781-107-11086-1, accessed June 28, 2021. https://doi.org/10.1017/CBO9781316275511. https://www.cambridge.org/core/books/taxation-responsiveness-and-accountabilityin-subsaharan-africa/FB29D1D344E94A7E34FA29B449D14215.

Queralt, Didac. 2019. "War, international finance, and fiscal capacity in the long run." International Organization 73 (4): 713-753. 
Robbins, Michael. 2019. Algeria Protests 2019. Topic Report. Arab Barometer, August. https://www.arabbarometer.org/wp- content/uploads/ABV_Algeria_Protests_PublicOpinion_Arab-Barometer_2019.pdf.

Ross, Michael. 2001. "Does oil hinder democracy?" World Politics 53 (3): 325-361.

— 2006. "A Closer Look at Oil, Diamonds, and Civil War." Annual Review of Political Science 9 (1): 265-300. Accessed July 20, 2021. https://doi.org/10.1146/annurev . polisci.9.081304.161338. https://doi.org/10.1146/annurev.polisci.9.081304.161338. 2012. The oil curse: How petroleum wealth shapes the development of nations. Princeton: Princeton University Press.

2015. "What Have We Learned about the Resource Curse?" Annual Review of Political Science 18 (1): 239-259. Accessed June 28, 2021. https://doi.org/10.1146/annurevpolisci-052213-040359. https://doi.org/10.1146/annurev-polisci-052213-040359.

Slater, Daniel, Benjamin Smith, and Gautam Nair. 2014. "Economic origins of democratic breakdown? The redistributive model and the postcolonial state." Perspectives on Politics $12(2)$.

Smith, Benjamin, and David Waldner. 2021. "Rethinking the Resource Curse." Elements in the Politics of Development (April). Accessed September 7, 2021. https://doi.org/ 10.1017/9781108776837. https://www.cambridge.org/core/elements/rethinking- theresource-curse/98A68DF4E64A08EE1BCCA3099A49118F.

Tilly, Charles. 1992. Coercion, capital and european states, AD 990-1992. Cambridge, MA: Blackwell.

Waldner, David. 1999. State building and late development. Cornell University Press. 
Waldner, David, Brenton Peterson, and Jon Shoup. 2015. "Against the grain of urban bias: Elite conflict and the logic of coalition formation in colonial and post-colonial africa." April.

Waldner, David, and Benjamin Smith. 2021. "Survivorship Bias in Comparative Politics: Endogenous Sovereignty and the Resource Curse." Perspectives on Politics 19, no. 3 (September): 890-905. ISSN: 1537-5927, 1541-0986, accessed September 7, 2021. https: //doi.org/10.1017/S1537592720003497. https://www.cambridge.org/core/journals / perspectives-on-politics/article/survivorship-bias-in-comparative-politics-endogenoussovereignty-and-the-resource-curse/E7CC75B211A7CCE246C2C27B10ABD593.

Wang, Wei, David Rothschild, Sharad Goel, and Andrew Gelman. 2014. "Forecasting elections with non-representative polls." International Journal of Forecasting.

Waterbury, John. 1983. The egypt of nasser and sadat: The political economy of two regimes. Princeton University Press.

Weiss, Linda, and John M Hobson. 1995. States and economic development: a comparative historical analysis. Polity Press Cambridge.

Weyland, Kurt. 2012. "The arab spring: Why the surprising similarities with the revolutionary wave of 1848?" Perspectives on Politics 10 (4): 917-934.

Zoubir, Yahia H. 2019. "Algeria After the Arab Spring" (August 13, 2019). ISSN: 0015-7120, accessed April 18, 2022. https://www foreignaffairs.com/articles / algeria/2016-0209/algeria-after-arab-spring. 